\title{
The emergence of the publicly engaged research manager
}

\author{
Katherine Dunleavy* - University of Bristol, UK \\ Michael Noble - University of Nottingham, UK \\ Heidi Andrews - University of Bristol, UK
}

\begin{abstract}
The increasing spread and rising profile of publicly engaged research in the UK has been accompanied by the emergence of a new, specialized professional services role embedded within research project teams. With this in mind, the Public Engagement Professionals in University Research Network convened a survey and workshop in 2017 to critically examine the skills and experiences of individuals in administrative roles in such projects. This paper argues that this is a highly skilled role that blurs boundaries between academic, administrator and engagement professional, but within higher education institutions it is often poorly understood and, therefore, undervalued and unsupported.
\end{abstract}

Keywords: collaborative research; research administration; hybrid identities; co-production; community facilitation; networks

\section{Key messages}

- The publicly engaged research manager role has developed over recent years with a growing emphasis on collaborative and co-produced research.

- Such roles do not sit comfortably in either purely administrative or academic work profiles, nor do they fit within the school/departmental structures of most universities.

- It is important that funders and universities understand the skills required for these roles, which are often undervalued 'soft skills', as well as practical project management abilities, and appoint them with an appropriate number of weekly hours and suitable salary grade.

\section{Background}

In recent years, public engagement with research, as a distinctive mode of academic activity, has become increasingly common, and increasingly encouraged by funders and regulators in the UK (NCCPE, 2015). The impact agenda, and the metrics of the Research Excellence Framework (REF) in particular, has led to universities looking for new ways to engage with local communities in order to demonstrate or amplify the 'impact' of their research. Alongside this, there has been a proliferation of academic writing that seeks to understand how to improve engagement and partnerships (for example, Burchell et al., 2017; Facer and Enright, 2016; INVOLVE, 2018). Despite this 
interest, little attention has been paid to a key role in many research teams, that of the publicly engaged research project manager.

We recognize that the term used in the title of this article - 'publicly engaged research manager' - is not widely used. However, in the absence of a common descriptor for these roles, largely due to a lack of consistency in job titles across the public engagement field, we have used it here to describe positions with a shared set of characteristics. First, these roles are primarily focused on delivering research projects; this means that they are likely to be externally funded through a research grant and embedded in an academic team, rather than be part of a centralized university structure. However, they are broadly administrative and 'professional services', rather than academic, posts with responsibility for managing, among other things, budgets, data, communications and adherence to local and funder policies. We use the term 'manager' to reflect the autonomy and oversight of the role but acknowledge that this is a shorthand for a variety of levels of experience and varying job titles. (We discuss the issue of a title for this role in more depth later in the article.) Second, the research that they support is characterized by an emphasis on public engagement; this is usually through co-production, but they may use other forms of participation. As we will see, the project manager is therefore required to support not only an academic team but also networks of community participants, partners and interested parties, as well as engaging with the public more broadly about the research process and findings.

Many of the community-university projects funded under the Arts and Humanities Research Council's (AHRC) Connected Communities programme employed a dedicated project manager. For these projects, this professional administrative role has been responsible for a wide range of project activities, has played an essential part in the development and improvement of bureaucratic systems, and has helped to bridge the gap between campus and community. Reviewing university-community collaborations in Creating Living Knowledge, Facer and Enright (2016: 157) suggest that in order for high-quality collaborative research partnerships to be sustained, 'University professional services require training and support, as well as more agile and adaptable systems, to enable processes in HR, finance and legal departments that are adequate for partnership working with multiple small-scale partners.' In this paper, we address the contribution of professional services to projects by focusing on the role of the project manager.

The paper is based on data gathered through the Public Engagement Professionals in University Research (PEPUR) Network, and, in particular, via a skills survey and workshop of project managers that sought to understand the role of the project manager within collaborative research and to examine the practical working conditions of these roles. It begins by reviewing the background to the network and the wider professional context of the project manager role in collaborative research, before proceeding to look at the findings of the survey and workshop in 2017. We finish by looking at the potential future of these roles in the higher education (HE) sector and making some initial recommendations for research organizations employing research project managers.

\section{The Connected Communities programme and the creation of the network}

A popular approach to engagement has been to co-produce research with partner organizations. Co-production requires the academic and community partner in a project to jointly design the research questions, process and outputs. A significant 
funder of co-produced research for the last seven years has been the Connected Communities programme, led by the AHRC and established to 'build powerful research collaborations between researchers and communities that reflect the challenges and interests of diverse communities' (AHRC, n.d.: 4). It was grounded in, and has been a key contributor to, the ongoing 'participatory turn' in research, in which relationships between the academy and the community have been bolstered by the collaborative pursuit of research projects (Facer and Enright, 2016). By 2016, the scheme had funded over three hundred projects, each of which included at least one community partner from the outset and through every stage of the research process. Projects were encouraged to be exploratory in their methods and outputs, and researchers were drawn from a wide variety of disciplines. The 'community partners', the common term used to describe non-university research collaborators (Enright and Facer, 2017: 14), were similarly varied.

The unique challenges of co-produced or participatory research have been well documented by the Connected Communities programme, and by other similar projects and reports, such as the N8, NCCPE and Mind the Gap reports (Campbell and Vanderhoven, 2016; NCCPE, 2015; Dillon et al., 2014). All of these reports argue that co-production requires specific and dedicated management, and that successful projects invest significant time, both to build relationships, and to plan and review the project. The Mind the Gap report, for example, concluded that 'the more partners, subject specialisms and individual researchers involved in a collaborative project the stronger the need for careful project management' (Dillon et al., 2014: 5). It is essential that these research projects build strong and honest relationships within the collaborative team, and expert brokerage and networking are required to bring the right people together while ensuring that the day-to-day project activities are completed. Therefore, an individual supporting these projects may spend their day juggling competing and diverse tasks, from arranging catering to mediating between partners, from paying expenses to writing a strategy and presenting it to the board. Buys and Bursnall (2007) argue that interpersonal skills are the most influential and important ingredient in university-community partnerships and, although a range of skills are needed in the role, it seems likely that those working in multi-partner projects will be more reliant on so-called 'soft skills' (see also Wechsler, 2017 for a personal account of the importance of learning interpersonal skills in collaborative research).

Many, though not all, of the Connected Communities projects recruited nonacademic staff to support the researchers and partners. According to AHRC data, 96 projects received funding for a post under the category 'other', which is used for nonacademic project staff. In most cases, this funding was for a project manager role. As these project managers began to cross paths informally, seek each other out and meet via chance encounters at conferences, it became apparent that these people, although they were usually employed as 'professional services' staff (as defined by their formal job family in their host university), were often embedded within academic faculties and reported receiving little tailored support from either the funders or their institutions.

PEPUR was established in 2015 to informally bring together those fulfilling these administrative roles within the Connected Communities programme. Initially, the network operated as a support group to allow professionals to come together to share best practice (or establish some notions of best practice in an emerging field) and to offer personal and emotional support. It was clear to the members that if the network wanted their roles to be taken seriously by universities and funders, then a greater understanding of the unique skills and expertise on offer had to be developed, 
alongside an understanding of the potential barriers to doing the job well and building a career as a research project manager.

\section{The changing nature of roles in higher education}

The role of the publicly engaged research manager has developed at a time when identities and roles within HE have undergone a significant shift. The binaries between 'academic' and 'professional' are increasingly being challenged, and new approaches to working that require flexibility, creativity and strong interpersonal skills are becoming more prevalent. However, like many large institutions, universities can be slow to adapt to the changes, which often leaves staff in hybrid and emergent positions unrecognized, unsupported and vulnerable to changes, both in their immediate project team and in institutional and funding priorities. Although research has not previously been conducted into these roles, there is literature that looks at the changing working contexts in universities and that focuses on two distinct roles with much in common with the research project manager, that of the public engagement professional, a new and emerging role also related to the growing impact agenda, and the research administrator, who supports academics from a centralized team.

Celia Whitchurch has written extensively about the changing nature of roles within the HE sector. She particularly emphasizes that as labour in universities becomes more project-based, both academic and administrative staff are likely to find themselves working in teams that do not sit within traditional university structures or perform conventional university tasks such as teaching, something that Whitchurch (2008) labels the 'third space'. Although not an example she uses specifically, public engagement activities and engaged research seem to belong within such a space. Additionally, Whitchurch $(2009,2006)$ has looked at those working in this space, a group she describes as 'blended professionals', who she defines as working in dedicated appointments that span professional and academic domains, contributing to new knowledge but not employed on academic contracts. Whitchurch (2008) highlighted the potential issues of blurring the distinction between 'academic' and 'professional roles', including the risk of an ambiguity that can lead to a lack of legitimacy and formal authority.

Despite primarily working in a third space, research project managers and other engagement professionals are usually deemed to be 'professional services' staff, which can be to their disadvantage. Szekeres (2011) argues that administrative staff in HE are effectively an underclass in pay, conditions and flexibility. Allen-Collinson (2006), looking at research administrators, finds that many are invisible in the HE hierarchy because, even when they have equivalent qualifications to academic colleagues, their non-academic identity leads to them being undervalued. On the other hand, Gander et al. (2014) make a strong case for the idea that non-academic staff in universities should not be ashamed of their identities and should value the alternative skills and expertise they bring. Job titles can also be a source of contention. Whitchurch (2006) found that, for professional services staff, terms such as 'administration' and 'management' lacked precision and were felt to be negative in an HE context. Gander et al. (2014: 5-6) also raise the 'naming' issue for 'non-academic' roles, noting the stigma of being a 'manager' in a university.

Furthermore, because new roles are so poorly understood in an HE environment that seeks to centralize as much administrative work as possible in a drive for efficiency (Fish, 2005; Hussey and Smith, 2010), job descriptions and recruitment processes are inadequate. The State of Play report found that recruitment panels hiring professionals 
for engagement roles often do not know what type of person and key skills they are looking for (Owen et al., 2016: 18-19). Similarly, the training, development and line management of hybrid roles are poorly managed. Whitchurch (2008) shows that project-based professionals who work across boundaries often raise issues about development and how this relates to their academic colleagues, who are seen to be better supported.

With these challenges in mind, our research set out to understand how the publicly engaged research manager role fits within the wider picture of increasing professionalization within public engagement and $\mathrm{HE}$, and asked what are the unique skills required for these roles, what working conditions they operate under and what needs to be done to ensure that the role offers maximum benefit to all stakeholders in publicly engaged research.

\section{Methods}

Although formed with dedicated Connected Communities project managers in mind, the scope of the PEPUR network also offers membership to those in centralized professional services roles that provide support to the projects, such as research development managers and public engagement officers. This allows the network to embed the experiences, activities and recommendations of research project managers in the wider HE context. The network holds meetings approximately every six months, to offer networking and support, as well as focused conversation on key topics such as finance procedures, event planning and continuing professional development.

Over the lifetime of the network, data have been collected informally through the experiences and ideas shared at these regular meetings, and through information gathered in collaborative online documents. However, in 2017 we (the authors with the support of the wider network) decided to supplement this data through a survey and workshop that focused specifically on the skills required to manage collaborative research.

\section{Shared network data}

The establishment of a JiscMail mailing list had been the first step in bringing the network together in 2015, and by the time of the workshop it had 27 members from 18 $\mathrm{HE}$ institutions across the UK. All network members and participants in this research are self-selecting and, therefore, are likely to be motivated, proactive individuals, perhaps with a particular interest in career development, or those in need of specific support.

The network also shares documents through Google Drive. This facilitates communication but also allows us to understand the membership of the network. The directory in this shared folder includes not only contact details, but also job titles, a description of the role, the contract type (for example, fixed-term or open-ended, and contract end dates) and the institutional employer of members. Members also use the folder to share the person specifications for their roles and any documents they find useful, for example articles relating to finance policies. This allows members to reflect on challenges and best practice.

Both the mailing list and shared folders were set up to enable members to share (and remove) their own information and documents to allow them to choose their own level of participation. The documents and data were also already public facing - for example, contact details and guidance documents were available on institution websites - so the folders acted primarily as a place to bring information together for comparison and comment. 


\section{The skills survey}

The authors, who convened the workshop and who are also members of the network, agreed that the goal of the network's activity in 2017 should be to identify the nature of its members, define the role(s) that they filled, and assay the nature of skills and expertise they required to discharge their responsibilities. The first step in gathering this information was a survey of network members about skills and training.

Members of the mailing list were surveyed as to the skills that they possessed and that they used in their work. They were encouraged not only to consider the skills defined in the person specification for their role, but also previously undocumented skills that they have had to deploy in their work. They were also asked to review any training that they had received, either in their current role or in a previous one. An online spreadsheet was made available for respondents to anonymously add their skills. This spreadsheet was available for a period of four weeks. Two tables were provided in this spreadsheet:

- A Skills and experience table, encompassing a list of skills (y axis) and short descriptions of how they were used in practice ( $x$ axis). Respondents were invited to contribute to both the $x$ and $y$ axes, adding any skills that they used that were not currently listed and updating the descriptions to better reflect their own experiences. Several columns were available along the $x$ axis so that no one had to overwrite a previous respondent's work.

- A Training table, for which respondents were asked to add the topic of the training, a brief description of it and information on whether it was delivered by an external organization or their own institution, whether it was accredited and any qualification that resulted.

The exercise was designed to allow all project managers in the network to participate, and the goal was to map as many skills as possible. Respondents were instructed to add as much, or as little, as they liked, and were advised that they did not have to complete their entry in one go - they were able to access and edit the sheet as many times as they liked before the advertised closing date. This was intended to capture 'hidden skills', those attributes that are often unconsidered by role-holders until the moment they actually use them. In total, 35 skills and descriptions were entered into the skills and experience table and 39 entries were made in the training table. Owing to the anonymous nature of the tables, it is not possible to see how many individuals contributed entries or to associate the entries with any detail about individual roles. However, the purpose of the tables was not to gather a comprehensive data set; it was designed as a scoping exercise to facilitate in-depth discussion at the workshop.

Once the data gathering process was closed, the authors reviewed the responses, and edited the documents for clarity and to remove duplication. This created a list of 19 skills, which were organized into a series of 'skill families':

- project management

- outreach and community

- line management

- finance/contracting/compliance

- communication

- technical

- HE institution specialist knowledge.

This skills survey formed the basis of the workshop activities. Specifically, this list was used to create a self-diagnostic tool that was used in the workshop to allow participants 
to rate how important they thought individual skills were to their roles. The list of skills and the rankings from the workshop can be found in Table 1.

Table 1: Ranking of skills needed for the role, where 1 represents the most important

\begin{tabular}{lc}
\hline \multicolumn{1}{c}{$\begin{array}{c}\text { What are the most important skills and knowledge when undertaking a } \\
\text { partnership project? }\end{array}$} & Rank \\
Skill/Knowledge & 1 \\
Diplomacy and negotiation & 2 \\
Academic and community relationship support & 3 \\
Relationship management & 4 \\
Community and/or public outreach & 5 \\
Project management & 6 \\
Finance/budget management & 7 \\
Using social media for research and engagement & 8 \\
Preparing briefings & 8 \\
Writing for publication (including websites, newsletters) & 10 \\
Preparing and writing reports & 10 \\
Media liaison & 12 \\
Planning and designing a user-centred website/WordPress site & 13 \\
Public speaking & 14 \\
Contract negotiation & 15 \\
Knowledge of databases & 16 \\
Delivering coaching/mentoring/training & 17 \\
Recruitment & 18 \\
Knowledge of Microsoft Project and/or other project management tools & 19 \\
Staff review and development &
\end{tabular}

\section{The workshop}

The one-day workshop was held in July 2017 in Bristol. Participants were selfselecting, prompted by promotion of the event through the PEPUR mailing list and the Connected Communities mailing list. In total, 16 participants ( 11 female and 5 male) from ten UK universities and representing a variety of career stages attended the workshop, facilitated by a consultant from Shared Service Architects. This is a private company that specializes in developing tools to facilitate collaboration in the public sector. We worked with the facilitator to adapt their Developing the Shared Vision tool to understand the commonalities and differences across research manager roles. External facilitation allowed all members of the group to participate in the activities and brought expertise from other sectors into the workshop.

It was important to create a space in which participants felt able to share potentially sensitive information about their role, career, team and employer, so the day began with an exercise to establish ground rules. It was agreed that the workshop would operate under the Chatham House Rule; any reports would be anonymized (both names and institutions), and documents or recommendations drawn from the workshop would be shared with the group for any follow-up comments. 


\section{The structure of the day}

The workshop was organized into several participatory activities designed to give participants time to reflect on their roles and skill sets, before building to a final activity that focused on the project manager's position within the 'big picture' of research and $\mathrm{HE}$.

The activities were as follows:

- Ideal job description - in groups of four, participants critiqued an example job description for a project manager role, removing tasks and skills that did not apply to them and adding any that were missing.

- Skills and competencies - using the skills audit conducted with the network mailing list, participants ranked the skills they considered most important in their role.

- Working conditions - participants anonymously indicated their contract type, salary bracket and weekly contracted hours.

- The big picture - in small groups using pictures and role-play, participants adopted one of four personas, each representing a different stakeholder in collaborative research, and created a narrative about the potential benefits of their role from the perspective of the adopted persona.

\section{Workshop feedback}

Each participant provided feedback in a short, anonymous survey at the end of the day. One of the key messages to emerge from this feedback was that, as professionals, the time and resource to reflect upon their role and career was greatly appreciated and that it is often not possible to do this with colleagues who work in similar projects within an institution. Attendees also reported a sense of confirmation of their opinion that there was a defined role that needed support, and that they were willing to advocate for providing better structure and more appreciation of the specific skills required. When asked what positive message they would take away from the event, one participant said: 'That my role is important and valued'. Other statements supported the core aims of the network and the workshop in offering support and opportunities to share: 'very happy to know that experiences are shared widely', 'working together can implement change', 'I think the support of a network and role-specific training would make a huge difference'. This suggests that resourcing such networks and allowing opportunities for often isolated individuals to come together is vital.

\section{Findings}

Our research suggests that in the Connected Communities programme, the project manager role went beyond the usual expectations of research administration and was vested with a variety of responsibilities dedicated to maintaining the relationship between university and community, and in making projects successful. Consequently, this role developed into a hybrid of project management, community liaison, relationship management, research administration and a variety of other responsibilities, some of which only became apparent once the project was under way.

One of the striking aspects of the skills review was the breadth of duties that role-holders were required to fulfil in the course of their normal work. Role-holders were, and are, expected to discharge a variety of tasks to an extent that defies simple categorization. This could range from providing project participants with emotional 
support to liaising with web developers, from writing a data management strategy to helping community organizations develop accounting procedures. Although some of these tasks were in job descriptions, a great many were not. Offering both emotional and practical support were significant and time-consuming elements of the job rarely referenced in job descriptions, and this is reflected in the skill set discussed below. These duties often took the project manager into the third space, requiring them to operate outside of the normal administrative structure of the university while being limited to the administrative sphere in terms of pay, training and conditions.

\section{Skills}

We found that a broad skill set was required to perform these roles effectively, including many practical administrative tasks, but there was a clear need in these roles for 'soft skills'. The most valuable such skill in our survey was 'diplomacy and negotiation', with 'academic and community relationship support' second and 'relationship management' third (see Table 1 for a full breakdown of skills and order of importance). This suggests that current job descriptions and development opportunities that focus on traditional administrative skills may undervalue the skills that individuals bring to these roles. Of the job descriptions we collected from the network, only two put significant emphasis on 'good interpersonal skills' as an essential criterion in the person specification. Interestingly, both of these descriptions were written by project managers already in post during the process of re-evaluating their pay grade. More typical were practical skills and tasks typified in one description that put the work under the headings 'governance', 'day-to-day management', 'communication' (referring to websites, communication strategies and responding to emails) and 'archiving'.

Anecdotally, it has been clear from previous discussion at network meetings that job descriptions can be varied and, often, so inaccurate that they have to go through several adjustments once the employee is in the role. With this in mind, we spent time at the workshop examining the key things an ideal job description would include (by 'ideal' we mean that the job description accurately describes the role as performed, rather than 'dream job'). 'Soft skills' were almost universally overlooked in attendees' own job descriptions; therefore, the ability to 'build relationships', 'show empathy' and 'influence beyond institutional boundaries' were added to the ideal job description, as was experience in 'engaging hard-to-reach communities'. Other key skills built into the ideal job description reflected on the independent nature of the work, which can be largely self-managing within the research team. It was suggested that candidates should be 'flexible', 'creative' and 'resilient'. All of these additions reflect the broad description of soft skills in Matteson et al. (2016) and suggest there is a strong tendency towards using 'hard skills' in current recruitment practices.

The final ideal job description (see Appendix) shows that these roles require a breadth of experience and expertise. Significantly, skills not frequently listed in job specifications were highly important to those in the roles. The ability to work with people and different organizations is clearly more important in this job specification than knowledge of internal systems, which can perhaps be more readily acquired through in-house training. That being said, the requirements of this role show that in-depth knowledge of the sector is important, as the role-holder will often need to signpost important information to their team and manage the project on a day-today basis. 
Figure 1: Workshop participants collaborating on the review

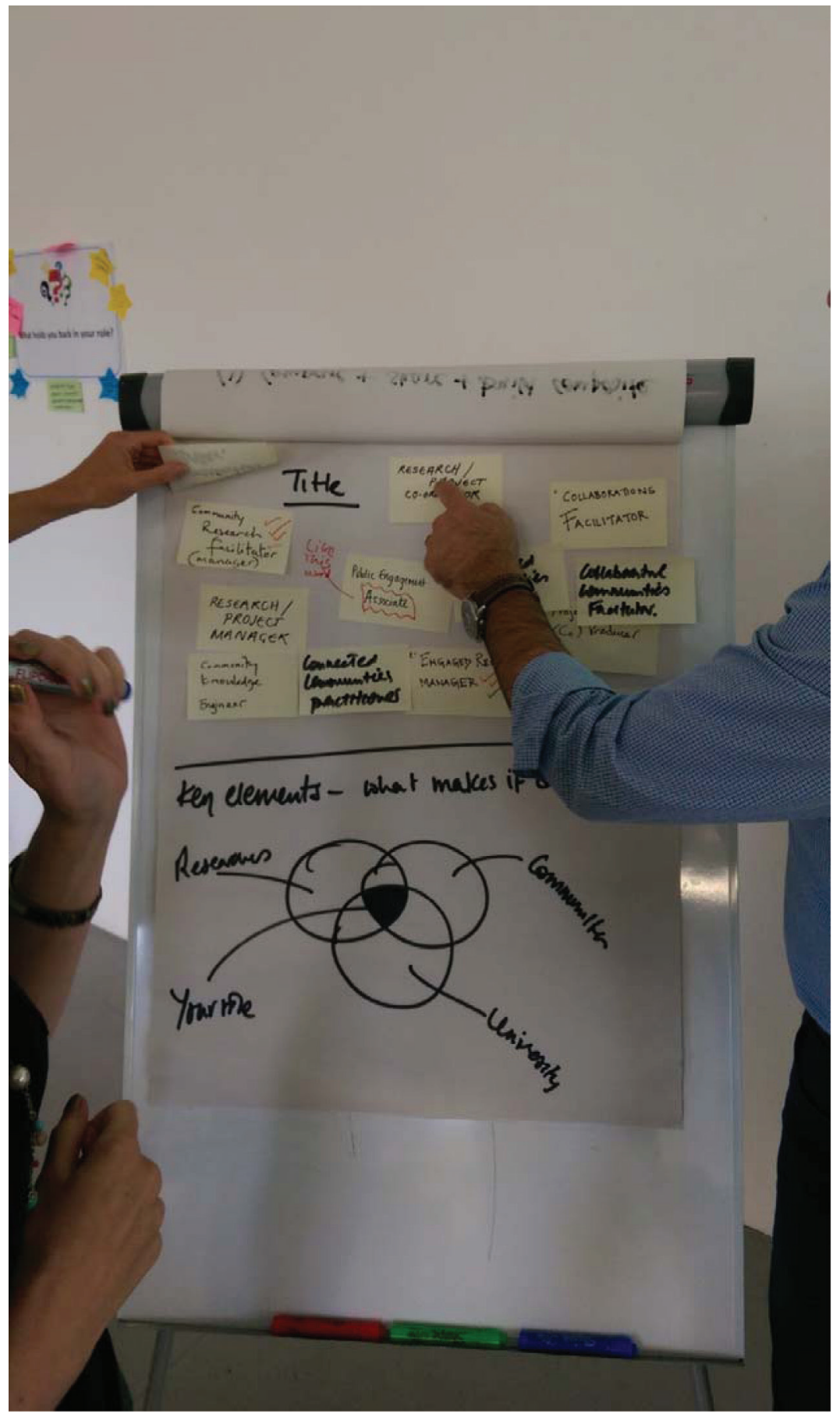

Credit: Michael Noble

There are also criteria in the job description that suggest the blurring of 'academic' and 'non-academic' tasks, for example presenting at conferences, and the breadth of tasks shows that this role deals with many aspects of university administration and external engagement. This further demonstrates the blurred nature of these roles. 


\section{Job titles}

It had not been our intention to focus on job titles. However, it was apparent in the workshop and the data we gathered that job titles lacked consistency and were an area of contention. The workshop group felt that the labels 'administrator' or 'manager', although commonly used in their job titles, were insufficient in conveying the fact that the most important skills were not process-based but interpersonal. It also often felt as though such titles implied that the roles had no parity with academics in the project team.

Terms such as 'facilitator', 'associate' and 'coordinator' were felt to be more appropriate as a description of the skills and abilities. The two titles most popular with the participants were 'community engagement coordinator' and 'collaborative research facilitator'; the term 'associate' was also popular as part of a job description. These titles were chosen because the participants' jobs went beyond the traditional ideas of management or administration, and the most significant part of their role was the ability to bring people together and help them to achieve research aims collaboratively. It was also apparent that many participants felt that terms such as 'manager' and 'administrator' carry negative connotations in HE environments and suggest that they are junior to academic colleagues. 'Associate' was suggested as a way to bring some parity between the role and that of researchers, as it is often used to describe junior research staff. The term 'associate' does not necessarily have connotations of increased job security or power within the HE environment. However, the recognition that the project manager role was as significant was important to some participants, particularly those with an academic background.

\section{Training and development}

It was apparent from discussions in meetings and via email that the group felt that their own career development was unsupported. Two of the more prominent reasons for this were that, first, there was no obvious career trajectory within their institutions and, second, role-holders were likely to have to move regularly between short-term contracts. The discussion in the workshop supported this view.

Although the focus of the workshop was on skills, we know from research into other project team members, such as early career researchers, that instability can be damaging (Enright and Facer, 2017), so we wanted to explore how consistently individuals were (financially) valued within institutions and the stability of employment. Most participants at the workshop were on part-time and fixed-term contracts, which causes some concern around skills retention (nine part-time and six fixed-term contracts). The inconsistency in the findings here also speaks to the need for some form of 'professionalization' or 'standardization' across the sector.

It was important to the participants that the role was as valued as academic roles within the project, without itself becoming an academic post. While it was acknowledged that an understanding of research practices was important and that some applicants may have doctoral qualifications, higher degrees should not become an essential qualification for the role, and possession of such a qualification alone did not make an individual suitable for a support role. There was also little appetite for a formal qualification specifically designed for such roles, similar to, for example, ARMA's Certificate in Research Administration. In terms of formal training gathered by our survey, the complexity and diversity of responsibilities within these roles are reflected in the types of training undertaken, which range from VAT and finance training to working with the media and understanding research evidence (a list of the 
training courses can be found in the form reproduced as Table 2). It is particularly clear from the skills review that a mix of academic, administrative and engagement-based competencies are required by these roles. Attendees suggested that they would be most interested in opportunities that allowed them to spend time understanding the community sector and relationships or academic training on communication, as this would be more valuable than typical project management courses such as Prince2.

\section{Table 2: The formal training undertaken by PEPUR network members}

\begin{tabular}{|c|c|}
\hline $\begin{array}{l}\text { What training have you received to support you in carrying out your } \\
\text { role? (Include training that you have received for this role and training you } \\
\text { have received elsewhere) }\end{array}$ & $\begin{array}{l}\text { Tick if } \\
\text { received }\end{array}$ \\
\hline \multicolumn{2}{|l|}{ Bid writing } \\
\hline \multicolumn{2}{|l|}{ Coaching skills for managers } \\
\hline \multicolumn{2}{|l|}{ Planning and designing a user-centred website } \\
\hline \multicolumn{2}{|l|}{ Writing effective and accessible web content for the university website } \\
\hline \multicolumn{2}{|l|}{ Handling difficult conversations } \\
\hline \multicolumn{2}{|l|}{ Managing team performance } \\
\hline \multicolumn{2}{|l|}{$\begin{array}{l}\text { Captivating places; captivating ideas; captivating people: unlocking the } \\
\text { potential of curiosity-driven engagement }\end{array}$} \\
\hline \multicolumn{2}{|l|}{ Managing successful projects } \\
\hline \multicolumn{2}{|l|}{ Staff review and development } \\
\hline \multicolumn{2}{|l|}{ Collaborating for success } \\
\hline \multicolumn{2}{|l|}{ Using and understanding research evidence } \\
\hline \multicolumn{2}{|l|}{ Enhancing facilitation skills workshop } \\
\hline \multicolumn{2}{|l|}{ Communication in organizations } \\
\hline \multicolumn{2}{|l|}{ Dealing with difficult situations } \\
\hline \multicolumn{2}{|l|}{ Equality, discrimination and law } \\
\hline \multicolumn{2}{|l|}{ Evaluating public engagement impacts } \\
\hline \multicolumn{2}{|l|}{ Evaluation and impact } \\
\hline \multicolumn{2}{|l|}{ Foundations of people management } \\
\hline \multicolumn{2}{|l|}{ Leadership for high-performing teams } \\
\hline \multicolumn{2}{|l|}{ Management } \\
\hline \multicolumn{2}{|l|}{ MS Project } \\
\hline \multicolumn{2}{|l|}{ Open access } \\
\hline \multicolumn{2}{|l|}{ PraxisUnico research contracts } \\
\hline \multicolumn{2}{|l|}{ Presentation skills } \\
\hline \multicolumn{2}{|l|}{ Project management } \\
\hline \multicolumn{2}{|l|}{ Recognizing and managing stress } \\
\hline \multicolumn{2}{|l|}{ Recruitment selection coordinator } \\
\hline \multicolumn{2}{|l|}{ Research project management } \\
\hline \multicolumn{2}{|l|}{ Staff review and development for managers } \\
\hline \multicolumn{2}{|l|}{ Successful recruitment and selection } \\
\hline Taking minutes and running effective meetings & \\
\hline Time management & \\
\hline Using social media for research and engagement & \\
\hline VAT and research finance & \\
\hline WordPress - web page creation and design & \\
\hline Working with the media & \\
\hline
\end{tabular}




\section{Why is this role needed?}

The workshop allowed us to better understand how having an individual with these skills in a project could benefit a variety of stakeholders. We encouraged participants to begin to think of their roles as contributing to the wider HE sector, and to develop confidence in the value of their role, as there are few formal ways to appreciate the value of such work.

\section{Figure 2: One of the stakeholder personas created in the workshop}

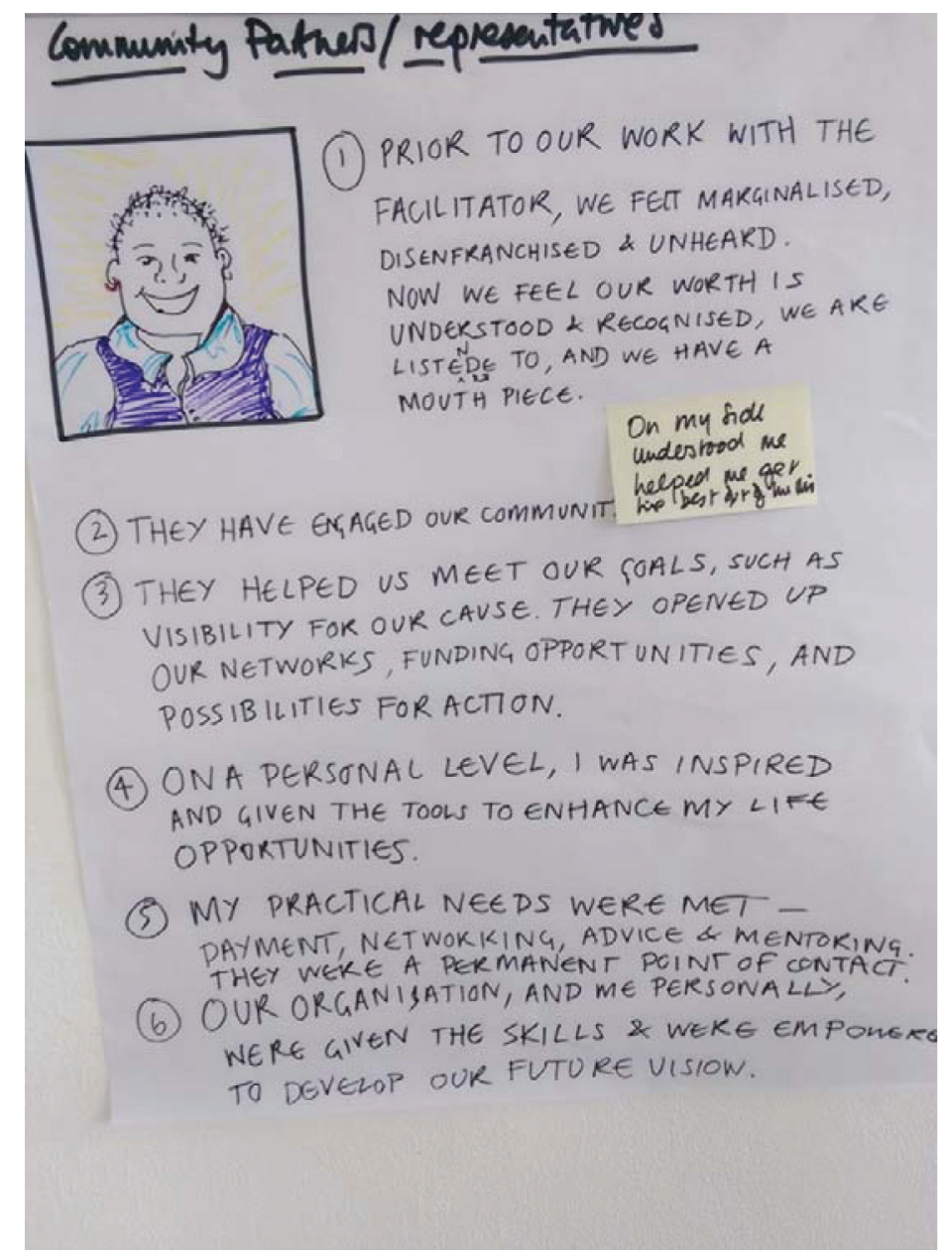

Credit: Michael Noble

We also felt that it was important to begin to understand the benefits of these roles so that it is possible to begin to collectively encourage institutions to appreciate and take seriously the merits of such employees. The main tasks that focused on this included creating personas involved in projects (see, for example, Figure 2). This encouraged participants to discuss the value and importance of their work through the voice of another and, thus, more easily to express their feelings without embarrassment or modesty. Several key areas were highlighted as benefiting from the involvement of a project manager, and these are discussed below. 


\section{Relationships with community partners}

Workshop participants explained that, in their experience, community partners benefited from having a regular point of contact who understood their needs and could engage in a dialogue with them. They could also help to give the partner a voice within the institution by guiding them through processes and ensuring that practices were fair and ethical. In the exercise, workshop participants created general personas to reflect people with whom they had worked. 'Janice' the community partner was imagined saying, 'They have helped us meet our goals, such as visibility for our cause. They opened up our networks, funding opportunities and possibilities for action.' At a strategic level, these roles could help to foster good relationships with local communities, and in that way could help universities with their aims to be responsible public institutions. 'Sandra' the imaginary vice chancellor said, 'We've built strong local relationships that demonstrate our core values.' It is also worth noting that research project managers often hold a key position in maintaining the relationships within their immediate project teams and with a wide variety of other departments in the university. The support they provide to community partners, although vital, is only one aspect of the relationship management and emotional support they provide.

\section{Efficient project management}

Researchers and, specifically, principal investigators could find that without dedicated administrative support they could inefficiently spend their own time trying to manage day-to-day administration, communications and relationships. They also could reduce pressure on themselves by having a reliable person in the team to whom tasks could be delegated. Participants imagined 'Professor Archimedes' saying, 'I didn't have to worry about holding things together' and 'This person was instrumental in creating and maintaining genuine partnerships.' At an institutional level, they assisted with good data management, efficient budget management and recording of impacts, which are all significant concerns for universities in the current audit-heavy climate.

\section{Finance}

One area in which a specialist intermediary stood out as being particularly useful is the navigation of university finance systems. In fact, our very first network meeting focused on challenges and best practice in the financial administration of collaborative research, and it has remained a frequent topic of discussion. The regulations and processes that govern research funding can be rather arcane, with terms such as 'directly incurred', 'directly allocated' and 'full economic costing' causing difficulties even for established academic staff. A degree of specialization is required to work effectively with university financing and, while this expertise is relatively abundant in administrative departments, it is often lacking in the partner-facing roles that are occupied by publicly engaged academics. Understanding the intricacies of these systems and, crucially, being able to communicate them effectively to non-specialists is a particular skill of the publicly engaged research manager. The absence of established processes for payments to community partners often requires personal intervention to find creative solutions to these challenges while managing the expectations of all parties in the relationship. This direct intervention is best made by a single point of contact, and responsibility usually falls to the publicly engaged research manager.

It is important to recognize that universities often have staff who focus on engagement, finance or good governance, but this particular role is distinctive in placing all of these duties on a single person (or several people sharing a position 
in the case of job sharing), so that they can be managed with a high degree of personalization. The siting of the role in a third space between researcher, community partner and institution means that these diverse functions can be handled in a way that eases communication between the parties, with the university and with other participant organizations.

A further striking feature is the 'bottom-up' nature of the role. The role has evolved over time and, as it has done so, it has collected duties, responsibilities and skills as they have become necessary for the success of the project. This may go some way to explain the disparity between the job descriptions and the realities of the role.

\section{Individual benefits}

It has been very clear throughout this research that, although there are challenges in the ways project manager roles are understood in the emerging collaborative research context, the majority of post-holders are highly motivated by, and engaged with, their jobs. When asked about the difference they made to projects and the impact their work had on them as individuals, the response was overwhelmingly positive. Of particular value was the opportunity to work with communities. For example, one workshop participant said that they 'felt a real connection with partners', and another said that it was a 'privilege to work alongside an influential charity'. Others said that the complexity and demands of the role had actually 'built their confidence', 'developed their capabilities' and 'empowered' them. One group of workshop participants explained their position as follows:

The car was running but no one knew how it ran! (or why it broke down). One day somebody lifted the bonnet and all was revealed - light shone brightly on the component parts and my role as a cog in the wheel was made apparent ... I am proud to be a key part of an 'engine' that keeps the car running.

This captures the feeling of many participants that their job was often lacking visibility and misunderstood within the wider institution, but that they were proud to be part of the effectiveness of their teams, partnerships and research.

\section{Discussion}

\section{Blended professionals and the third space}

This research has shown that many of these project manager roles should be seen as 'blended professionals' as defined by Whitchurch (2009) and, therefore, the current provision of support does not address fully the specific needs of this role. They are often part of exploratory, challenging projects that they are pioneering and, as they create new ways of working with both partners and institutions, so the need for support and a community of professionals is even more pronounced for this group. It is perhaps a misnomer to describe this collection of responsibilities as a 'role' as, although the functions are often vested in a single employee, they appear in different degrees and with different levels of responsibility. Nevertheless, there are sufficient commonalities between role-holders to make a discussion of the nature of the role instructive and even essential.

This work has suggested that project managers focused on collaborative research have developed a particular skill set that allows them to cope with the demands of a role that requires not only practical project management but, more significantly, brokering, 
mediation and personal and emotional support for a wide variety of stakeholders. To date, universities have largely labelled this as an 'administrative' position and have based recruitment and training (where offered) around skills traditionally associated with such roles. However, this workshop has suggested that these skills, although relevant to some extent, are not the cornerstone of the project manager role. The implication of this is that role-holders are isolated and confused about their role, which, once in post, bears little resemblance to the one they applied for, and that the training and support offered by institutions is likely to be unsuitable. In line with the findings of the State of Play report (Owen et al., 2016), institutions and recruiters seem to be equally confused when composing job descriptions and making appointments. Recognition that these roles do not neatly fit within the 'administration' or 'professional services' model of most universities and operate within the 'third space' (Whitchurch, 2006, 2008) is key to understanding such roles and supporting them well, in turn allowing them to effectively support their projects, academic team members and community partners. While other research, such as the State of Play report, suggest that some of the issues around vague job descriptions and career progression are common to many emerging public engagement roles, the issues for research project managers are exacerbated by the tendency to appoint them on fixed-term contracts. This means that they are often looking for their next position relatively soon after joining a project and, therefore, require support to ensure that they are not unduly disadvantaged by working in this area.

At the most basic level, it is important that funders and universities seek to understand the skills required for these roles and appoint them with an appropriate number of weekly hours and salary grade. Appreciating the skills of these individuals, standardizing job descriptions and offering clear guidance to those writing grant proposals (so that such roles may be suitably funded) are essential to ensuring adequate support for the project manager and all of the other project stakeholders.

A recognition that interpersonal, creative and self-management skills, often deemed 'soft skills', are as valued as other technical skills is important for understanding and developing this role. Although we did not specifically aim to look at gender, the composition of our network suggests that these project management roles are often held by women. This seems to reflect general perceptions that roles associated with 'soft skills' are low status and characterized as feminine (Matteson et al., 2016). Better understanding and recognition of the complexities and high level of skills required to do these roles could help to address the gender imbalance in pay and status across $\mathrm{HE}$ (Shambrook et al., 2011; Gander et al., 2014).

\section{Job titles}

The strength of feeling among participants suggests that institutions need to ensure that job titles are more accurate, as generic labels can be demoralizing and lead to a loss of status for employees in all administrative roles, as suggested by Gander et al. (2014) and Whitchurch (2006: 168), but it is particularly pronounced in those who work closely with academic and community partners, where parity with other members of the team is important and recognition that the role extends beyond typical administrative tasks can be essential to build relationships. It seems that existing job titles are intentionally broad and bland, and describe an imperfect or partial view of the actual job. They are effectively a blank envelope in which to carry a wide range of responsibilities and shifting or ill-defined duties. Their strength for recruiters lies in their lack of precision, which allows the roles to change without needing to be rebranded or reassessed. It is also perhaps a reflection of how broadly defined the roles were when they were 
established. This is no doubt a symptom of the way these roles have evolved and developed through the programme, and suggests there was little clarity about the responsibilities at the outset.

\section{Professionalization?}

There has been a movement in several emerging roles in HE to encourage formal professionalization of roles, for example work on knowledge brokers (Bayley et al., 2017); although this comes with greater recognition, there are also concerns that it could hamper some of the flexibility and creativity of project manager roles and lead to pressure to introduce formal qualifications. Shambrook et al. (2011) have shown that in the US such qualifications do not on average lead to higher earnings, and it is difficult to imagine a qualification that could encompass the diversity of collaborative research. Hockey and Allen-Collinson (2009: 143) note that research administrators in all disciplines are often engaged in 'on the job' learning more than formal training, as they fall outside normal institutional regulations. This seems also to be true for those engaged in these project management roles. That being said, there is clearly room for improvements in training and working conditions, and a starting point would be to provide parity in contract terms and development opportunities to all those in a research team, rather than offering more favourable conditions for the academics.

The skills mapping in this research could be a starting point for future work that builds appropriate continuing professional development support for project managers that relates to the requirements of the role. The 'professional' categorization of these roles also leads to them being unsupported by the Vitae researcher development framework and concordat (www.vitae.ac.uk/policy/vitae-concordat-vitae-2011.pdf), despite the similarities in employment conditions between these roles and those of early career researchers. Extending the concordat to all those employed as part of a research project team could help to mitigate some of the problems with training provision and short-term contracts.

\section{Retention}

Fractional contracts and failure to offer career progression create a strong likelihood that these experts will leave institutions and that their knowledge and skills will be lost to HE. Given that it seems likely that public engagement and community collaborations will continue to grow as part of the profile of universities and may become increasingly part of metrics related to funding, as we have seen with REF and may see further in the Knowledge Exchange Framework (KEF) (Pells, 2018), it seems short-sighted of institutions not to recognize and support the expertise of their current staff rather than reinventing the wheel with every funding call.

\section{Conclusion}

Clearly, there is the potential for these roles to have wide-ranging benefits for all of the stakeholders of a research project and for HE institutions, but only if they are appointed on the basis of appropriate skill sets and working conditions, and if the expertise of individuals is utilized once they are in post. The workshop findings suggest that research project managers are enthusiastic about their roles and keen to help stakeholders achieve their goals. Therefore, developing and retaining these individuals could be of great benefit across the sector. We recommend three actions to better recognize and support these roles: 
- Universities and funders should use the experience of staff from completed projects to create parity across the sector, with more accurate job descriptions and appropriate job titles. These templates should foreground the soft skills that are essential to the job and de-emphasize technical skills that are less essential. Funders should supply them to research development departments and encourage their use in bids.

- Greater acceptance that these roles are neither wholly administrative nor academic should be actioned through protections equivalent to the researcher concordat and development framework. This should be championed by research funders and embedded by HE institutions in their staff development policies.

- Fractional contracts should only be used as a last resort. Institutions should be creative in developing posts that offer security to those taking on these roles and recognize the extensive time commitment that these duties require.

\section{Acknowledgements}

This work was funded by the AHRC Connected Communities Leadership Fellowship. Our thanks to Keri Facer for her constructive comments on drafts of this article and to our colleagues in the PEPUR network for their participation and support.

The PEPUR network continues to grow, and welcomes all those working in non-academic roles in research teams that have a focus on co-production or public engagement. The authors welcome enquiries from interested parties.

\section{Notes on the contributors}

Katherine Dunleavy is Coordinator for the Connected Communities programme, working alongside the Leadership Fellows. She leads on work, funded by the AHRC, to understand the administrative issues that can form barriers to engaged research.

Michael Noble is the Project Manager for the Centre for Hidden Histories, an AHRC First World War Engagement Centre based at the University of Nottingham. His responsibilities include community liaison, project development and relationship management. He is currently researching a PhD on the impact of the First World War on the development of the provincial university system in England.

Heidi Andrews has worked in university research administration for 18 years. For the last five years she was the Projector Coordinator on the ESRC-funded programme Productive Margins: Regulating for Engagement, based at the University of Bristol.

\section{References}

AHRC (Arts and Humanities Research Council) (n.d.) Connected Communities: Understanding the changing nature of communities in their contexts and the role of communities in sustaining and enhancing our quality of life. Swindon: Arts and Humanities Research Council. Online. https://tinyurl.com/y9t22x98 (accessed 4 November 2018).

Allen-Collinson, J. (2006) 'Just "non-academics"? Research administrators and contested occupational identity'. Work, Employment and Society, 20 (2), 267-88.

Bayley, J.E., Phipps, D., Batac, M. and Stevens, E. (2017) 'Development of a framework for knowledge mobilisation and impact competencies'. Evidence and Policy (in press).

Burchell, K., Sheppard, C. and Chambers, J. (2017) 'A "work in progress"?: UK researchers and participation in public engagement'. Research for All, 1 (1), 198-224.

Buys, N. and Bursnall, S. (2007) 'Establishing university-community partnerships: Processes and benefits'. Journal of Higher Education Policy and Management, 29 (1), 73-86. 
Campbell, H. and Vanderhoven, D. (2016) Knowledge that Matters: Realising the potential of co-production. Manchester: N8 Research Partnership.

Dillon, C., Bell, N., Fouseki, K., Laurenson, P., Thompson, A. and Strlič, M. (2014) 'Mind the gap: Rigour and relevance in collaborative heritage science research'. Heritage Science, 2, Article 11, 1-22. Online. https://tinyurl.com/y8e4u4la (accessed 4 November 2018).

Enright, B. and Facer, K. (2017) 'Developing reflexive identities through collaborative, interdisciplinary and precarious work: The experience of early career researchers'. Globalisation, Societies and Education, 15 (5), 621-34.

Facer, K. and Enright, B. (2016) Creating Living Knowledge: The Connected Communities Programme, community-university relationships and the participatory turn in the production of knowledge. Bristol: University of Bristol / AHRC Connected Communities.

Fish, S. (2005) 'Take this job and do it: Administering the university without an idea'. Critical Inquiry, 31 (2), 271-85.

Gander, M., Moyes, H. and Sabzalieva, E. (2014) Managing Your Career in Higher Education Administration. Basingstoke: Palgrave Macmillan.

Hockey, J. and Allen-Collinson, J. (2009) 'Occupational knowledge and practice amongst UK university research administrators'. Higher Education Quarterly, 63 (2), 141-59.

Hussey, T. and Smith, P. (2010) The Trouble with Higher Education: A critical examination of our universities. New York: Routledge.

INVOLVE (2018) Guidance on Co-Producing a Research Project. Southampton: INVOLVE.

Matteson, M.L., Anderson, L. and Boyden, C. (2016) '"Soft skills": A phrase in search of meaning'. portal: Libraries and the Academy, 16 (1), 71-88.

NCCPE (National Co-ordinating Centre for Public Engagement) (2015) Taking Stock: A review of university public engagement activity. Online. www.publicengagement.ac.uk/sites/default/files/ publication/taking_stock_report_final.pdf (accessed 30 November 2018).

Owen, D., Featherstone, H. and Leslie, K. (2016) The State of Play: Public engagement with research in UK universities. London: Research Councils UK / Wellcome Trust.

Pells, R. (2018) 'The shape of KEF to come'. Times Higher Education, 2341, 32-7.

Shambrook, J., Roberts, T.J. and Triscari, R. (2011) 'Research administrator salary: Association with education, experience, credentials and gender'. Journal of Research Administration, 42 (2), 87-99.

Szekeres, J. (2011) 'Professional staff carve out a new space'. Journal of Higher Education Policy and Management, 33 (6), 679-91.

Wechsler, A.M. (2017) 'Overcoming the Venn diagram: Learning to be a co-passionate navigator in community-based participatory research'. Research for All, 1 (1), 147-57.

Whitchurch, C. (2006) 'Who do they think they are? The changing identities of professional administrators and managers in UK higher education'. Journal of Higher Education Policy and Management, 28 (2), 159-71.

Whitchurch, C. (2008) 'Shifting identities and blurring boundaries: The emergence of third space professionals in UK higher education'. Higher Education Quarterly, 62 (4), 377-96.

Whitchurch, C. (2009) 'The rise of the blended professional in higher education: A comparison between the United Kingdom, Australia and the United States'. Higher Education, 58 (3), 407-18. 


\section{Appendix}

\section{Connected Communities Community Research Coordinator JOB DESCRIPTION}

To support academic and community partners in the development and management of a coproduced research project. The post-holder must be able to work effectively and sensitively with a range of colleagues across organizational boundaries and to support the project lead in all aspects of research project and team management.

\section{PERSON SPECIFICATION}

The qualifications, skills, knowledge and experience outlined below provide a summary of what is required to carry out this job effectively. They also form the selection criteria on which the decision on who to appoint will be made. Please ensure that you show how you meet the criteria outlined below in your application.

\section{COMMUNICATION AND INTERPERSONAL SKILLS \\ Essential \\ Desirable}

- Experience of building relationships and brokering conversations between a variety of stakeholders

- Excellent interpersonal skills, particularly empathy and understanding, and the ability to develop mutual trust within partnerships

- Ability to support a large and varied team practically, professionally and emotionally

- Experience of communicating/presenting information to academic, professional and public audiences

- Ability to select and use a range of tools for communication and promotion of the project

\section{KNOWLEDGE AND EXPERIENCE}

\section{Essential}

- Experience of managing complex financial and contractual issues

- Experience of managing projects across organizations with multiple stakeholders

- Ability to organize and facilitate a wide variety of events, including community engagement activities

- Experience liaising with designers and developers to build and maintain websites and databases

\section{RELEVANT QUALIFICATIONS}

\section{Essential}

- Educated to degree level or holding significant project management experience

\section{Essential}

- Ability to innovate, 'think outside the box' and find new ways of approaching problems

\section{ADDITIONAL CRITERIA}

- Experience of engaging with 'hard to reach' communities

- Good presentation skills, including presentations to academic conferences and community/policy events

- Experience of designing and maintaining a website

- Experience of using social media to engage audiences

- Ability to write press releases and liaise with the press or liaise with the press office

- Understanding of HE and research systems and procedures

- Ability to lead, or support the team leader, in recruitment and personnel support other relevant experience - Project management tools (for example Prince II)

\section{Desirable}

- $\mathrm{APhD}$ is not necessary for this role but an understanding of research in $\mathrm{HE}$ contexts is. This can be from a PhD or

\section{Desirable}

- Broad knowledge of the HE sector, particularly issues relating to research such as REF, open access publishing and data protection 